\title{
Homology and Comparative Methods in the Study of Avian Cooperative Breeding
}

\section{Citation}

Edwards, Scott V. and Shahid Naeem. 1994. Homology and comparative methods in the study of avian cooperative breeding. American Naturalist 143(4): 723-733.

\section{Published Version}

http://dx.doi.org/10.1086/285628

\section{Permanent link}

http://nrs.harvard.edu/urn-3:HUL.InstRepos:2664295

\section{Terms of Use}

This article was downloaded from Harvard University's DASH repository, and is made available under the terms and conditions applicable to Other Posted Material, as set forth at http:// nrs.harvard.edu/urn-3:HUL.InstRepos:dash.current.terms-of-use\#LAA

\section{Share Your Story}

The Harvard community has made this article openly available.

Please share how this access benefits you. Submit a story.

\section{Accessibility}




\section{CHICAGO JOURNALS}

\section{The American Society of Naturalists}

Homology and Comparative Methods in the Study of Avian Cooperative Breeding Author(s): Scott V. Edwards and Shahid Naeem

Source: The American Naturalist, Vol. 143, No. 4 (Apr., 1994), pp. 723-733

Published by: The University of Chicago Press for The American Society of Naturalists

Stable URL: http://www.jstor.org/stable/2462908

Accessed: $13 / 03 / 2009$ 13:12

Your use of the JSTOR archive indicates your acceptance of JSTOR's Terms and Conditions of Use, available at http://www.jstor.org/page/info/about/policies/terms.jsp. JSTOR's Terms and Conditions of Use provides, in part, that unless you have obtained prior permission, you may not download an entire issue of a journal or multiple copies of articles, and you may use content in the JSTOR archive only for your personal, non-commercial use.

Please contact the publisher regarding any further use of this work. Publisher contact information may be obtained at http://www.jstor.org/action/showPublisher?publisherCode=ucpress.

Each copy of any part of a JSTOR transmission must contain the same copyright notice that appears on the screen or printed page of such transmission.

JSTOR is a not-for-profit organization founded in 1995 to build trusted digital archives for scholarship. We work with the scholarly community to preserve their work and the materials they rely upon, and to build a common research platform that promotes the discovery and use of these resources. For more information about JSTOR, please contact support@ jstor.org. 


\section{NOTES AND COMMENTS}

\section{HOMOLOGY AND COMPARATIVE METHODS IN THE STUDY OF AVIAN COOPERATIVE BREEDING}

In an earlier article (Edwards and Naeem 1993), we presented a comparative analysis of cooperative breeding (CB) in perching birds (order Passeriformes). Using both discrete (categorical) and continuous data sets, we illustrated a number of ways in which comparative methods could help clarify the temporal origins of $\mathrm{CB}$ in various clades, ecological correlates of $\mathrm{CB}$, and patterns of interspecific variation in attributes such as group size. The commentary on our article by McLennan and Brooks (1993) makes three main points, each of which raises important issues about the biology and ecology of $\mathrm{CB}$ in birds as well as the application of comparative methods to behavioral data. The first point is that comparative analyses of behavioral traits based on trees derived from taxonomies or noncladistic methods (phenetic clustering), "neither of which produces a robust phylogenetic hypothesis of genealogy" (McLennan and Brooks 1993, p. 790), are nonetheless useful for those researchers recognizing the importance of examining evolutionary hypotheses in a phylogenetic context. This point echoes our own plea for increased interest in building robust trees for ecologically and behaviorally diverse groups of birds (see, e.g., Richman and Price 1992), particularly for cooperative breeders (see, e.g., Edwards and Wilson 1990).

The analyses in our article were based on trees built with varied sources of data and methods of analysis: cladistic analysis of morphology (fairy wrens, Malurus), phenetic analysis of morphology (New World wrens, Campylorhynchus), taxonomy (e.g., Australian treecreepers, Climacteris), phenetic analysis of molecular distance data (e.g., New World jays), and cladistic analysis of DNA sequence data (Australian babblers, Pomatostomus). We agree that phylogenies are always preferable to taxonomies in comparative analyses, and, to the extent that it is difficult to model morphological evolution phenetically (Felsenstein 1988), our analysis in these cases should be treated as tentative. But to state that "phenetic" analyses categorically do not produce "robust" phylogenetic hypothesesthereby implying that cladistic methods categorically produce better trees-is simply outdated. The philosophical underpinnings of cladistics are different from those of other methods, but this does not mean that "noncladistic" methods cannot yield truth in practice. Uncertainties in phylogenetic inference often lie more in limitations of data than in the particular method used (Miyamoto and 
Cracraft 1991), and all tree-building methods have a specific region of parameter space in which they work best (Hendy and Penny 1989; Zharkikh and Li 1993). Under some circumstances, methods traditionally labeled as "cladistic" can converge on the wrong tree as more data are accumulated (Felsenstein 1978; Hendy and Penny 1989; Penny et al. 1992). Furthermore, several recently proposed comparative tests (see, e.g., Felsenstein 1985; Garland 1992) require estimates of branch lengths, which are arguably better obtained with noncladistic methods or, at the very least, with corrections on a purely cladistic approach (Fitch and Bruschi 1987). The above caveats particularly apply to the class of data of increasing use to comparative biologists, namely, DNA sequence data (Felsenstein 1988). As noted by McLennan and Brooks (1993), modern comparative biology is a relatively young field; in our opinion it would be unfortunate if the philosophical divisions characterizing the rise of quantitative systematic methods in the late 1960s and encapsulated in McLennan and Brooks's statement were to recapitulate themselves in this new era of comparative methods.

\section{ARE COMMUNAL BREEDING SYSTEMS HOMOLOGOUS?}

McLennan and Brooks's second point is that CB may in fact subsume a class or group of characters because of the inherent diversity among CB systems (e.g., in breeding systems, types and numbers of helpers and contexts of helping), in which case treating $\mathrm{CB}$ itself as homologous even among closely related species might be unwarranted. The concept of homology is still being refined (see, e.g., Patterson 1988; Wagner 1989), particularly as it is applied to behavior (Lorenz 1950; Mayr 1958; Atz 1970; McLennan et al. 1988; Wenzel 1992). For the purposes of this note, we define homology as "similarity due to inheritance from a common ancestor'; a homologous relationship of a character in different taxa can often be inferred only by determining whether that character displays congruence with (defines similar monophyletic groups as) other characters (Patterson 1982). Since we never denied that CB has developed multiple times in distantly related lineages of birds (Edwards and Naeem 1993, p. 771), we assume that McLennan and Brooks (1993) restrict the discussion of homology to closely related groups for which a hypothesis of homology of CB is reasonable; thus, for example, we agree that $\mathrm{CB}$ in New Zealand pukekos (Porphyrio porphyrio), a nonpasserine bird, probably shares few if any phylogenetic correlates with $\mathrm{CB}$ in passerines such as Florida scrub jays (Aphelocoma coerulescens coerulescens).

Although the assumption (or inference) of interspecific homology among behaviors continues to prove useful for understanding the evolution of behavior (McLennan et al. 1988; Prum 1990), it has been applied primarily to individual actions, ritualized movements, and "motor" responses, rather than to social systems per se. Since the early comparative studies of CB, the persistent observation that alloparental behavior could be generated by multiple ecological and demographic mechanisms has not only compromised most attempts to generalize about CB across taxa (Smith 1990) but opens the possibility that CB may not be homologous even between closely related species. For example, one could argue that the multiple mechanisms for the origin of $\mathrm{CB}$ in New World jays proposed by 
Brown (1974) provide evidence that CB is not homologous among these species because it has arisen in diverse demographic contexts in different species (although other interpretations of this article are certainly possible). In another view, White et al. (1991) suggested that few aspects of CB are actually "inherited" or arise in any long-term historical sequence of events; rather, group living literally develops anew every generation because of a constellation of recurrent, uninherited (though perhaps biased) responses of individuals to a repeated set of social and physical environmental factors. That $\mathrm{CB}$ develops by such routes is evident in birds such as the Seychelles warbler (Acrocephalus sechellensis), which was reported to have "evolved" cooperative breeding in a five-year period of population growth (1968-1973; Komdeur 1992) - a time span probably too short for any appreciable population genetic change. In such cases, CB is more appropriately considered convergent (i.e., nonhomologous), not only between species, but within species across successive generations (Lambert and Hughes 1988).

McLennan and Brooks's claim that we and other evolutionary biologists confuse behavioral characters with character classes constitutes another reason not to consider CB systems homologues. Our article argues against this point of view. First and most important, although we acknowledged that $\mathrm{CB}$ has arisen multiple times within the Passeriformes, in most of the phylogenetic analyses we presented, CB arose very few times (often once) within specific groups; thus, CB (as defined in our article) fulfilled the primary criterion of homology, namely, congruence with other sets of characters (Patterson 1988; Prum 1990). Similarly, other authors have found evidence for congruence (hence, homology) in group behaviors that McClennan and Brooks would consider character classes because they occur in a variety of social and breeding contexts (e.g., territoriality and coloniality: de Queiroz and Wimberger 1993; queen number in social insects: Ross and Carpenter 1991). Second, we suspect that social systems, which are necessarily defined by interactions among multiple, easily delimitable parts (namely, individuals), merely bring into sharper focus the dichotomy between character and character class that we believe exists at nearly all levels in the biological hierarchy. Many biologists argue that the definition of a character is itself controversial (Pogue and Mickevich 1990). An organ considered a character by an anatomist might be considered a character class by a histologist or cell biologist (although arguments against attempts to consider characters or taxa at more than one biological level simultaneously have been proposed [Líden 1990]). Finally, even if $\mathrm{CB}$ were not homologous between species, it was not the only character considered in our article. We speculated that phylogenetic analysis of traits considered prerequisites for $\mathrm{CB}$ and group living (e.g., the "stimulusresponse" behaviors in Jamieson 1989, delayed breeding, mechanisms of kin recognition) would help clarify patterns of behavioral evolution in cooperative breeders; such prerequisite traits only seem less atomizable than communal breeding systems to organismic biologists but would presumably be considered good characters by McLennan and Brooks (1993).

A more stringent criterion of behavioral homology requires the identification of congruent physiological and genetic structures underlying that behavior (Atz 1970; Wenzel 1992; fig. 1); in our view, such a criterion would increase confidence 


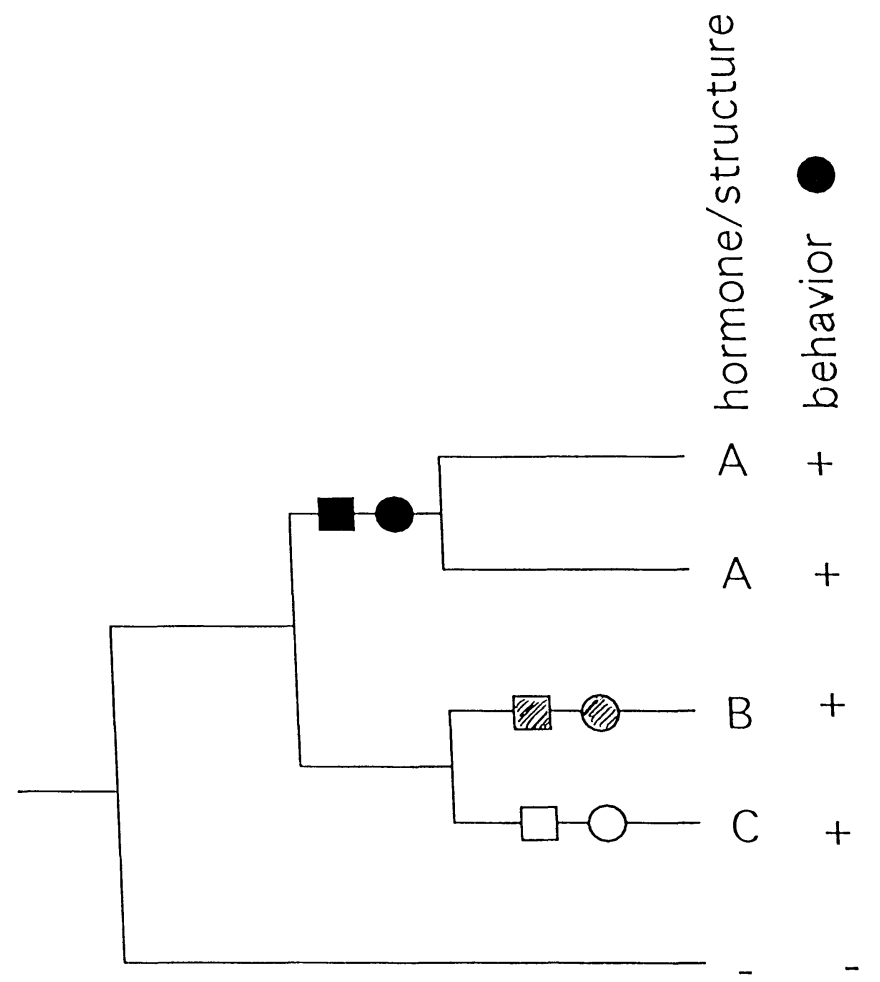

FIG. 1.-Hypothetical evolutionary tree illustrating the criterion of homology in behavior proposed by Atz (1970). Under "behavior," a plus symbol indicates phenotypic presence of a given trait, a minus symbol indicates phenotypic absence. Under "hormone/structure," letters designate different hypothetical hormones, structures, genes, or patterns of expression underlying the phenotype. When phenotypically similar behaviors in different species are known to originate in homologous hormones or structures (top two tips), the behaviors are considered homologous; these are indicated by black circles and squares representing behavioral and structural homologues, respectively. If they are known to originate in dissimilar or convergent physiological or structural contexts (indicated by white and stippled squares), they are considered nonhomologous between species (white and stippled circles).

in the search for behavioral homologues in cooperative breeders. Identifying the molecular bases of morphological changes has proved extremely effective in clarifying homologies in morphological evolution (see, e.g., Patel et al. 1989). Such efforts could help pinpoint aspects of CB that are homologous to behaviors found in noncooperative species, or-a more exciting prospect-behavioral components in cooperative breeders that are truly derived with respect to noncooperative species (Jamieson 1989). Although some argue that there are no truly derived behavioral or physiological processes distinguishing cooperative breeders from 
nonsocial species (White et al. 1991, p. 250), there are few data, and it is not known whether such derived processes exist. Patterns of hormonal expression are known to differ among, for example, bird species displaying varying levels of male parental care (Wingfield 1991). In many respects, whether derived homologues exist in cooperative breeders is the central issue in recent debates about CB (see references in Jamieson 1991); identifying similarities and differences in the tangible components of these behaviors could help resolve these debates.

We attempted to reconcile the plasticity observed so often in CB with our inference of phylogenetic conservatism by positing variation in the expression of more conservative behavioral or structural prerequisites of $\mathrm{CB}$, as in a threshold character whose state depends on interactions with the environment (see also Mumme 1992). More thoroughly studied communal systems not only illustrate the relationship we envision between such prerequisites and their expression as social behavior but provide a mechanism for their phylogenetic conservatism. We refer to the recent identification of some of the genes responsible for mediating mating preferences, kin recognition, and social interactions in mice (Potts et al. 1991; Manning et al. 1992). Although the type of social behavior arising from such a genetic system in different species would depend on the rules by which individuals process the information provided by that system, the genetic component of the social behavior would still be homologous among taxa because a specific set of inherited factors common to mammals would have been identified (Klein 1986).

Referring to cases in which "different" (i.e., nonhomologous) forms of CB are mistakenly lumped together under one category, McLennan and Brooks (1993, p. 791) argue that "there is no a priori reason to expect to find ecological correlates for its [CB's] evolution." We disagree. On the contrary, the ecological correlates and the adaptive basis of behaviors are probably best detected in cases of behavioral convergence (nonhomology; Ridley 1983). The presence of auxiliaries to the breeding pair is the cornerstone of $\mathrm{CB}$, and much of the literature on CB seeks to determine the ecological and demographic correlates of this trait despite the diversity observed in mating systems and sex and number of helpers. Different forms of CB are all nonetheless characterized by "helpers"; these variations can usefully be considered character states, comparison of which can yield an improved picture of the ecological correlates of CB (Peterson and Burt 1992). Thus the critical question regarding McLennan and Brooks's (1993) concern is not whether CB is a character or a character class but whether it forms a group of traits with functions similar enough that ecological correlates may be expected.

ECOLOGICAL CORRELATES OF CB DETECTED USING PHYLOGENIES: THE IMPORTANCE OF MODELS

Finally, McLennan and Brooks (1993) point out that in most cases we did not have enough information to draw firm conclusions about ecological correlates of CB because $\mathrm{CB}$ was plesiomorphic (i.e., ancestral) to several groups. We agree; as stated above, finding potential correlates for the origin of $\mathrm{CB}$ requires multiple 
derivations of CB within the clade of interest (Ridley 1983; Maddison 1990). We were surprised to find that $\mathrm{CB}$ arose so deeply in groups in which $\mathrm{CB}$ was well studied but for which close out-groups have not been identified (e.g., Australian wrens [Malurus + Stipiturus + Amytornis] and babblers [Pomatostomus]). In the one case in which the latter criterion was possibly fulfilled (Eopsaltria robins), the phylogenetic relationships of the species in question were ambiguous. McLennan and Brooks (1993) presented two possible resolutions of the ambiguous relationships of Eopsaltria georgiana (their fig. 2), but a third resolution exists: that in which E. georgiana composes the out-group to Eopsaltria australis, Eopsaltria flaviventris, and Eopsaltria griseogularis. This third alternative in fact corresponds to the cladistic analysis of Cracraft (1982) (whom we neglected to cite in our original article) and implies a scenario similar to that in McLennan and Brooks's figure 2b. Clearly, an understanding of the origins of CB in Eopsaltria must await a comprehensive phylogenetic analysis of all its members and relatives.

Models for the maintenance of CB solely via specific ecological regimes predict (1) a phylogenetic coincidence between the invasion of specific ecological regimes and the origin of $\mathrm{CB}$ and (2) a loss of $\mathrm{CB}$ coincident with lineages leaving such regimes. McLennan and Brooks (1993) acknowledge that detecting the latter pattern does not necessarily require that $\mathrm{CB}$ be derived within the clade of interest. Thus we found that several hypothesized ecological correlates of CB were in fact ancestral to the entire clade composed of both cooperative and noncooperative species (fig. $1 B$ of Edwards and Naeem 1993), thereby weakening ecological explanations for macroevolutionary trends in CB. In Pomatostomus and Malurus, CB persists in descendant lineages despite radical shifts in ecological regime, which again weakens causal links with CB (fig. 1C of Edwards and Naeem 1993). Our article was written in part to challenge claims based on nonphylogenetic analyses that there were well-supported ecological correlates of CB (e.g., in Australian passerines); with the caution that a more rigorous comparative analysis should be done, our preliminary findings are in agreement with those nonphylogenetic studies that failed to detect ecological correlates of CB (see, e.g., Dow 1980; Brown 1987).

The case of Eopsaltria robins illustrates an important methodological issue. As elsewhere (e.g., Brooks and McLennan 1990), McLennan and Brooks are here more concerned with qualitative evidence of causal relationships than with formal hypothesis testing and estimation of correlations (e.g., by Ridley's [1983] or Maddison's [1990] tests). As with any comparative analysis, the significance of correlations between CB and ecological parameters will depend on the model of character evolution chosen (Harvey and Purvis 1991). This effect is illustrated with simulations in figure 2 , in which both the time span in which CB is assumed to arise $(t)$ and the probability of change in CB $(\alpha)$ influence the strength of correlations of CB with ecological variables. Early in our analyses we were well aware that, "because the reconstructions of CB on the trees generally involved one or a few origins per group, we could not hope to achieve statistically significant associations of $\mathrm{CB}$ and other variables within any taxonomic group using existing tests that assume parsimony. . . Although the trait of interest [CB] may be 

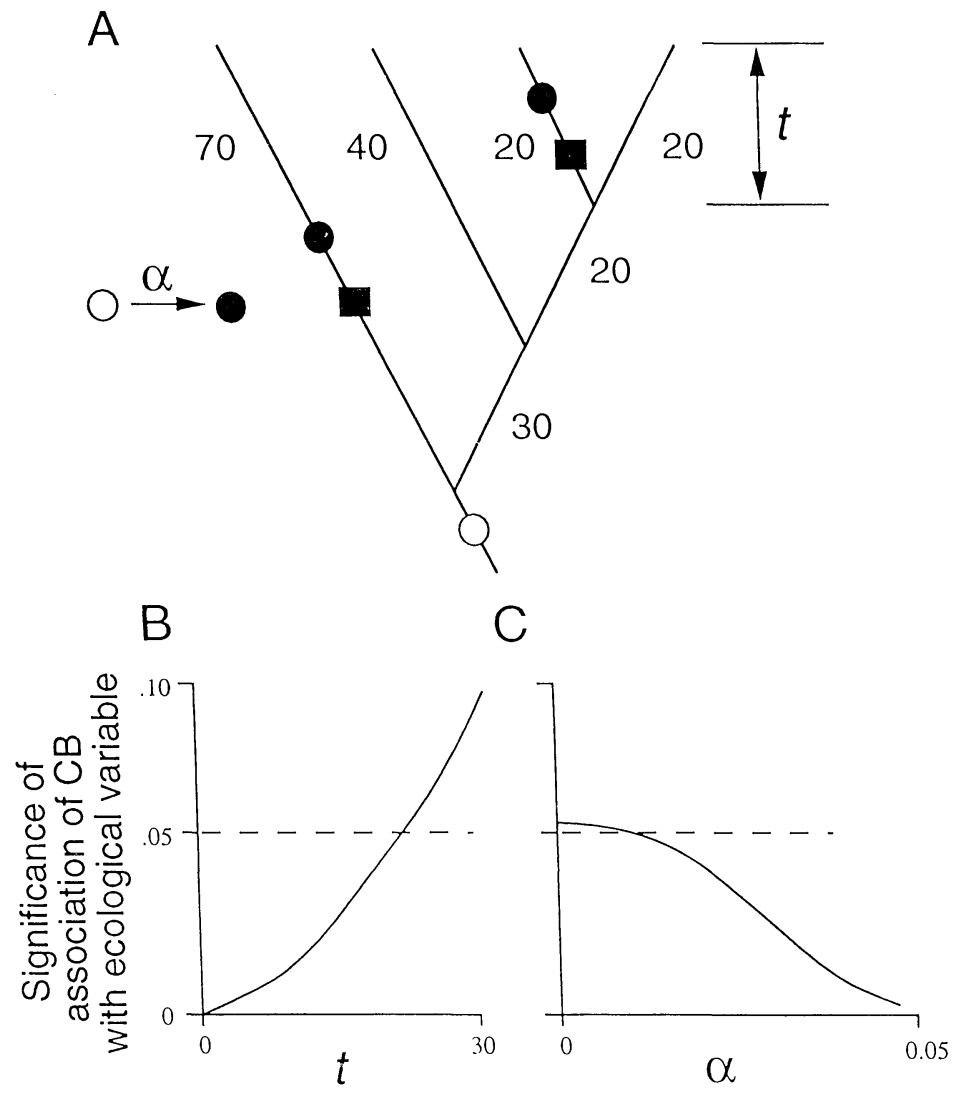

Fig. 2.-Assumptions about the evolution of cooperative breeding influence the statistical significance of correlations with ecological variables. A, Hypothetical tree of four species, with branch lengths indicated in arbitrary time units. Solid circles indicate transitions to cooperative breeding from an ancestral state (open circle) with probability $\alpha$ (inset). Solid squares indicate a derived ecological regime. The two terminal branches bracketed with a $t$ were varied in the simulations in $B$, as was $\alpha$ in $C$. The tree and character distributions are identical to those in the example in box 4.6 of Harvey and Pagel (1991). $B$, Simulations showing the effect of varying the two terminal branch lengths $t$ in $A$ ( $X$-axis) on the probability of observing the associations of cooperative breeding and the ecological variable in $A$ ( $Y$-axis) by chance. This probability is $P(Y \mid X)$, where $Y$ is cooperative breeding and $X$ is the ecological variable (Maddison 1990; Harvey and Pagel 1991). Ecological correlations with behavioral traits will in general appear much stronger when the time span during which the transitions are assumed to have occurred decreases. The horizontal dashed line indicates the traditional $P=.05$ cutoff value. As $t$ was varied from 0 to 40 , the branch below $t$ was varied from 40 to 0 such that the sum of these two lengths was always 40 . For each $t$ chosen, the corresponding maximum-likelihood value of $\alpha$, the probability of a transition to cooperative breeding, was calculated by reiteration as described (Harvey and Pagel 1991, pp. 101-103). The method used to compute $P(Y \mid X)$ is that of Maddison (1990), as formulated in a maximum-likelihood framework by Harvey and Pagel (1991). $C$, Effect of varying the probability of a transition to cooperative breeding, $\alpha$, on the strength of correlations of cooperative breeding with an ecological variable. In this particular example, as the evolution of cooperative breeding becomes increasingly likely, the significance of correlations with ecological variables increases, although the specific relationship between $P(Y \mid X)$ and $\alpha$ is strongly dependent on the particular reconstruction of characters, as we have observed other types of relationships for other reconstructions (e.g., positive or "humped" curves). Branch lengths are as in $A$, dashed horizontal line as in $B$. The model used is again that of Harvey and Pagel (1991), except here arbitrary values of $\alpha$ were chosen and applied to the reconstruction on the tree. 
deemed an adaptation to a hypothesized factor because it displays a few instances of appropriate relationship to that factor, nonetheless, inferring a causal relationship from these associations would not be supported by the criteria of existing parsimony tests" (Edwards and Naeem 1993, p. 758; italics added). We do not imply that more complex models would enhance associations in our study; the conservatism of both CB and ecological traits on many of the trees ensures that the probabilities of change and time spans required to achieve significant associations would probably be unrealistic. In addition, in the case of robins, it would be difficult to interpret significance or nonsignificance by a method other than parsimony since the branch lengths in this case are unknown. But it is a striking result that several recent tests of correlated evolution of discrete behavioral and ecological characters have failed to detect statistically significant associations of traits that traditional analyses had suggested were highly correlated (see, e.g., Höglund 1989; Maddison 1990; Read and Nee 1991), either because the associations are indeed unsupported given the size of available data sets or because the models of character (e.g., parsimony) are unrealistic.

In practice, the results of parsimony and statistically consistent methods such as maximum likelihood converge when branch lengths as measured by expected amounts of character change are small but can conflict under other circumstances (Farris 1973; Felsenstein 1979, 1983; Goldman 1990). As a result, the statistical significance of a particular distribution of $\mathrm{CB}$ and ecological variables will depend in part on the model assumed (fig. 2; Harvey and Pagel 1991; Martins and Garland 1991). For example, we pointed out that both the frequency (about $3 \%$ among all birds) and complexity of $\mathrm{CB}$ suggest that it is much more difficult for lineages to gain CB than to lose it. This suspicion justifies the use of models able to detect and incorporate asymmetries in probability of change (Sanderson 1993). More realistic models for both discrete and continuous characters are being developed (see, e.g., Martins and Garland 1991; Janson 1992) and will be crucial to extracting more information from comparative data in conjunction with quantitative estimates of the phylogenies themselves.

\section{ACKNOWLEDGMENTS}

We thank J. Cracraft, J. Felsenstein, P. Harvey, I. Jamieson, M. Miyamoto, R. Mumme, M. Pagel, W. Potts, T. Price, and particularly A. de Queiroz for helpful discussion and comments on the manuscript, although not all of these individuals agree with everything presented here. S.V.E. was supported by an Alfred P. Sloan Postdoctoral Fellowship in Molecular Evolution.

LITERATURE CITED

Atz, J. W. 1970. The application of the idea of homology to behavior. Pages 53-74 in L. R. Aronson, E. Tobach, D. S. Lehrman, and J. S. Rosenblatt, eds. Development and evolution of behavior: essays in memory of T. C. Schneirla. W. H. Freeman, San Francisco.

Brooks, D. R., and D. A. McLennan. 1990. Phylogeny, ecology and behavior. University of Chicago Press, Chicago. 
Brown, J. L. 1974. Alternate routes to sociality in jays-with a theory for the evolution of altruism and communal breeding. American Zoologist 14:63-80.

1987. Helping and communal breeding in birds: ecology and evolution. Princeton University Press, Princeton, N.J.

Cracraft, J. 1982. Geographic differentiation, cladistics, and vicariance biogeography: reconstructing the tempo and mode of evolution. American Zoologist 22:411-419.

de Queiroz, A., and P. H. Wimberger. 1993. The usefulnes of behavior for phylogeny estimation: levels of homplasy in behavioral and morphological characters. Evolution 47:4660.

Dow, D. D. 1980. Communally breeding Australian birds with an analysis of distributional and environmental factors. Emu 80:121-140.

Edwards, S. V., and S. Naeem. 1993. The phylogenetic component of cooperative breeding in perching birds. American Naturalist 141:754-789.

Edwards, S. V., and A. C. Wilson. 1990. Phylogenetically informative length polymorphism and sequence variability in mitochondrial DNA of Australian songbirds (Pomatostomus). Genetics 126:695-711.

Farris, J. S. 1973. A probability model for inferring evolutionary trees. Systematic Zoology 22:250256.

Felsenstein, J. 1978. Cases in which parsimony or compatibility methods will be positively misleading. Systematic Zoology 27:401-410.

1979. Alternative models of phylogenetic inference and their interrelationships. Systematic Zoology 28:49-62.

1983. Parsimony in systematics: biological and statistical issues. Annual Review of Ecology and Systematics 14:313-333.

1985. Phylogenies and the comparative method. American Naturalist 125:1-15.

1988. Phylogenies and quantitative characters. Annual Review of Ecology and Systematics 19:445-471.

Fitch, W. M., and M. Bruschi. 1987. The evolution of prokaryotic ferredoxins-with a general method correcting for unobserved substitutions in less branched lineages. Molecular Biology and Evolution 4:381-394.

Garland, T. 1992. Rate tests for phenotypic evolution using phylogenetically independent contrasts. American Naturalist 140:509-519.

Goldman, N. 1990. Maximum likelihood inference of phylogenetic trees, with special reference to a Poisson model of DNA substitution and to parsimony analyses. Systematic Zoology 39: 345-361.

Harvey, P., and M. Pagel. 1991. The comparative method in evolutionary biology. Oxford University Press, Oxford.

Harvey, P., and A. Purvis. 1991. Comparative methods for explaining adaptations. Nature (London) 351:619-624.

Hendy, M. D., and D. Penny. 1989. A framework for the quantitative study of evolutionary trees. Systematic Zoology 38:297-309.

Höglund, J. 1989. Size and plumage dimorphism in lek-breeding birds: a comparative analysis. American Naturalist 134:72-87.

Jamieson, I. 1989. Behavioral heterochrony and the evolution of birds' helping at the nest: an unselected consequence of communal breeding? American Naturalist 134:394-406.

1991. The unselected hypothesis for the evolution of helping behavior-too much or too little emphasis on natural selection? American Naturalist 138:271-282.

Janson, C. H. 1992. Measuring evolutionary constraints: a Markov model for phylogenetic transitions among seed dispersal syndromes. Evolution 46:136-158.

Klein, J. 1986. Natural history of the major histocompatibility complex. Wiley, New York.

Komdeur, J. 1992. Importance of habitat saturation and territory quality for evolution of cooperative breeding in the Seychelles warbler. Nature (London) 358:493-495.

Lambert, D. M., and A. J. Hughes. 1988. Keywords and concepts in structuralist and functionalist biology. Journal of Theoretical Biology 133:133-145.

Líden, M. 1990. Replicators, hierarchy and the species problem. Cladistics 6:183-186. 
Lorenz, K. 1950. The comparative method of studying innate behavior patterns. Symposia of the Society for Experimental Biology 4:221-268.

Maddison, W. P. 1990. A method for testing the correlated evolution of two binary characters: are gains or losses concentrated on certain branches of a phylogenetic tree? Evolution 44: 539-557.

Manning, C. J., E. K. Wakeland, and W. J. Potts. 1992. Communal nesting patterns in mice implicate MHC genes in kin recognition. Nature (London) 360:581-583.

Martins, E. P., and Garland, T., Jr. 1991. Phylogenetic analysis of the correlated evolution of continuous characters: a simulation study. Evolution 45:534-558.

Mayr, E. 1958. Behavior and systematics. Pages 341-366 in A. Roe and G. G. Simpson, eds. Behavior and evolution. Yale University Press, New Haven, Conn.

McLennan, D. A., and D. R. Brooks. 1993. The phylogenetic component of cooperative breeding in perching birds: a commentary. American Naturalist 141:790-795.

McLennan, D. A., D. R. Brooks, and J. D. McPhail. 1988. The benefits of communication between comparative ethology and phylogenetic systematics: a case study using gasterosteid fishes. Canadian Journal of Zoology 66:2177-2190.

Miyamoto, M. M., and J. Cracraft. 1991. Phylogenetic inference, DNA sequence analysis, and the future of molecular systematics. Pages 3-17 in M. M. Miyamoto and J. Cracraft, eds. Phylogenetic analysis of DNA sequences. Oxford University Press, Oxford.

Mumme, R. 1992. Delayed dispersal and cooperative breeding in the Seychelles warbler. Trends in Ecology \& Evolution 7:330-331.

Patel, N. H., T. B. Kornberg, and C. S. Goodman. 1989. Expression of engrailed during segmentation in grasshopper and crayfish. Development 107:201-212.

Patterson, C. 1982. Morphological characters and homology. Pages 21-74 in K. A. Joysey and A. E. Friday, eds. Problems of phylogenetic reconstruction. Academic Press, London.

1988. Homology in classical and molecular biology. Molecular Biology and Evolution 5: 603-625.

Penny, D., M. D. Hendy, and M. A. Steel. 1992. Progress with methods for constructing evolutionary trees. Trends in Ecology \& Evolution 8:73-79.

Peterson, A. T., and D. B. Burt. 1992. Phylogenetic history of social evolution and habitat use in the Aphelocoma jays. Animal Behaviour 44:859-866.

Pogue, M. G., and M. F. Mickevich. 1990. Character definitions and character state delineations: the bête noire of phylogenetic inference. Cladistics 6:319-361.

Potts, W. J., C. J. Manning, and E. K. Wakeland. 1991. Mating patterns in seminatural populations of mice influenced by MHC genotype. Nature (London) 352:619-621.

Prum, R. O. 1990. Phylogenetic analysis of the evolution of display behavior in the Neotropical manakins (Aves: Pipridae). Ethology 84:202-231.

Read, A., and S. Nee. 1991. Is Haldane's rule significant? Evolution 45:1707-1709.

Richman, A., and T. Price. 1992. Evolution of ecological differences in the Old World leaf warblers. Nature (London) 355:817-820.

Ridley, M. 1983. The explanation of organic diversity: the comparative method and adaptations for mating. Clarendon, Oxford.

Ross, K. G., and J. M. Carpenter. 1991. Phylogenetic analysis of queen number in the eusocial Hymenoptera. Journal of Evolutionary Biology 4:117-130.

Smith, J. N. M. 1990. Summary. Pages 593-611 in P. B. Stacey and W. D. Koenig, eds. Cooperative breeding in birds: long-term studies of ecology and behavior. Cambridge University Press, Cambridge.

Wagner, G. P. 1989. The origin of morphological characters and the biological basis of homology. Evolution 43:1157-1171.

Wenzel, J. W. 1992. Behavioral homology and phylogeny. Annual Review of Ecology and Systematics 23:361-381.

White, C. S., D. M. Lambert, C. D. Millar, and P. M. Stevens. 1991. Is helping behavior a consequence of natural selection? American Naturalist 138:246-253.

Wingfield, J. C. 1991. Mating systems and hormone-behavior interactions. Acta XX Congressus Internationalis Ornithologici 4:2005-2012. 
Zharkikh, A., and W.-H. Li. 1993. Inconsistency of the maximum-parsimony method: the case of five taxa with a molecular clock. Systematic Biology 42:1113-1125.

Scott V. Edwards*
Center for Mammalian Genetics and Department of Pathology, ioo275 UNIVERSITY OF FLORIDA

Gainesville, Florida 32640

NERC Centre for Population Biology

ShaHid NAEEM

Imperial College at Silwood Park

Ascot, Berkshire SL 57 PY, United Kingdom

Submitted November 23, 1992; Revised July 8, 1993; Accepted July 20, 1993

* Address for correspondence. E-mail: edwards@cmg.health.ufl.edu. 